\title{
Electrochemistry of nanoscale DNA surface films on carbon
}

\author{
A.M. Oliveira-Brett*, A.M. Chiorcea Paquim, V.C. Diculescu, J.A.P. Piedade \\ Departamento de Química, Faculdade de Ciências e Tecnologia, Universidade de Coimbra, 3004-535 Coimbra, Portugal
}

Received 28 April 2006; accepted 4 May 2006

\begin{abstract}
A DNA electrochemical biosensor is an integrated receptor-transducer device. The most important step in the development and manufacture of a sensitive DNA-biosensor for the detection of DNA-drug interactions is the immobilization procedure of the nucleic acid probe on the transducer surface. Magnetic A/C Mode atomic force microscopy (MAC Mode AFM) images in air were used to characterize two different procedures for immobilising nanoscale double-stranded DNA (dsDNA) surface films on carbon electrodes. Thin film dsDNA layers presented holes in the dsDNA film that left parts of the electrode surface uncovered while thicker films showed a uniform and complete coverage of the electrode. These two procedures for preparing dsDNA-biosensors were used to study the influence of reactive oxygen species (ROS) in the mechanism of DNA damage by quercetin, a flavonoid, and adriamycin, an anthracycline anticancer drug. The study of quercetin-DNA interactions in the presence of $\mathrm{Cu}$ (II) ions indicated that the formation of a quercetin- $\mathrm{Cu}$ (II) complex leads to the formation of ROS necessary to react with DNA, disrupting the helix and causing the formation of 8-oxo-7,8-dihydro-2'-deoxyguanosine (8-oxodGuo). Reduced adriamycin radicals are able to directly cause oxidative damage to DNA, generating 8-oxodGuo and ROS are not directly involved in this genomic mutagenic lesion.
\end{abstract}

(C) 2006 IPEM. Published by Elsevier Ltd. All rights reserved.

Keywords: Electrochemical DNA-biosensor; AFM; Nanoscale; Nanobioelectrochemistry; Surface films; Quercetin; Adriamycin

\section{Introduction}

Many compounds interact with DNA, causing modifications to the DNA structure and sequence, leading to perturbations in DNA replication. The chemical modification of DNA bases is called mutagenesis, and is produced by DNA damage, due to its exposure to toxic chemical compounds. Therefore, in a health prevention perspective, the need for analysis of DNA interactions with molecules and ions led to the development of DNA-biosensors.

A DNA electrochemical biosensor is an integrated receptor-transducer device that usually contains two basic components connected in series: an electrochemical transducer coupled with a DNA matrix as biological recognition element, in order to detect both DNA damage and DNA damaging agents. Interaction of DNA with the damaging agent is converted, via changes in the electrochemical

\footnotetext{
* Corresponding author. Tel.: +351 239 835295; fax: +351 239835295 .

E-mail address: brett@ci.uc.pt (A.M. Oliveira-Brett).
}

properties of the DNA recognition film, into measurable electrical signals.

The first and most important step in DNA-biosensor preparation consists in the immobilization and stabilization of the DNA molecules at the electrode surface. The different structures and conformations that DNA molecules can adopt at the electrode surface lead to different types of interaction and to the modification of the accessibility of the chemical compounds to the DNA grooves. Consequently, the understanding of DNA-biosensor surface morphological characteristics is essential for its practical application and for a better understanding of the voltammetric results obtained.

Magnetic A/C Mode atomic force microscopy (MAC Mode AFM) is a gentle technique that permits the direct visualisation of biomolecules that are softly bound to the electrode surface [1] and can bring important information about the internal morphology of DNA electrochemical biosensors. MAC Mode AFM was used to investigate the overall surface topography of the DNA based biosensor obtained by adsorption of dsDNA molecules on the electrode surface. 


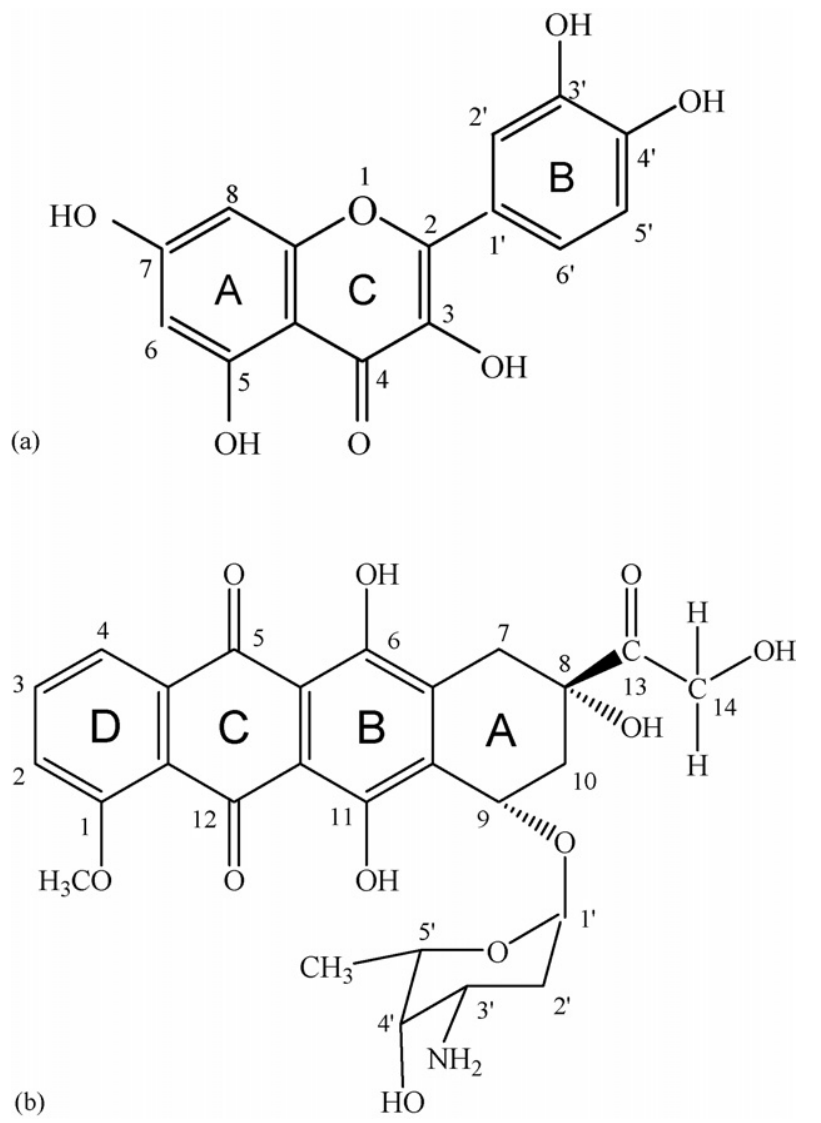

Scheme 1. Structure of: (a) quercetin and (b) adriamycin.

The interaction of several substances with dsDNA has been successfully studied using such kinds of biosensor, the results contributing to the elucidation of the mechanisms of DNA damage by hazardous compounds [2-10].

Quercetin, Scheme 1(a), is a flavonoid that often exhibits strong anti-oxidant properties [11]. In contrast with this commonly accepted role, there is evidence that quercetin is mutagenic and has DNA damaging ability [12,13]. The effect of quercetin on DNA has been studied using voltammetric detection $[9,10]$. The results indicated that oxidation of quercetin leads to the formation of a semiquinone radical that disrupts the helix by intercalation and leads to the formation of 8-oxo-7,8-dihydro- $2^{\prime}$-deoxyguanosine (8-oxodGuo), the principal product of guanine oxidation in DNA [14]. On the other hand, there is evidence that quercetin could indirectly damage DNA. In the presence of transition metals quercetin is auto-oxidizing and this process leads to the formation of reactive oxygen species (ROS) [11-13]. The effect of these oxygen radicals in the mechanism of DNA damage by quercetin has been investigated here.

Adriamycin, Scheme 1(b), is an antibiotic of the family of anthracyclines with a wide spectrum of chemotherapeutic applications and anti-neoplasic action. In previous work $[7,8,15]$ the adriamycin-dsDNA interaction was studied electrochemically using the DNA-biosensor. It was shown that the DNA-biosensor is a good tool to identify the reactions involved in DNA damage by adriamycin and a mechanistic model was proposed based on the electrochemical data [7]. Furthermore, the results indicated that adriamycin intercalated in double stranded DNA (dsDNA) is still electroactive, being able to undergo oxidation or reduction and reacting specifically with the guanine moiety. This leads to the formation of the mutagenic 8-oxodGuo.

The catalytic generation of ROS by adriamycin involved the formation of a semiquinone anion radical intermediate that reduces molecular oxygen to the superoxide radical followed by the regeneration of the quinone function moiety [16]. This homogeneous adriamycin- $\mathrm{O}_{2}$ redox-cycling process increases ROS generation without adriamycin consumption, occurs in vivo and can enhance ROS damage to the components of the living cell [17].

In this context, the aim of the present paper is the morphological characterization of the DNA-biosensor surface and the study of the influence of reactive oxygen radicals in the mechanism of DNA damage by quercetin and adriamycin.

\section{Experimental}

\subsection{Materials}

Adriamycin (doxorubicin hydrochloride, $2 \mathrm{mg} / \mathrm{mL}$ solution) obtained from Pharma-APS, quercetin and sodium salt calf thymus DNA (type II) from Sigma, $\mathrm{CuSO}_{4}$ obtained from Merck were used without further purification.

Solutions in $\mathrm{pH} 4.5,0.1 \mathrm{M}$ acetate buffer electrolyte of different concentrations of adriamycin, stock solutions of $500 \mu \mathrm{M}$ saturated quercetin, $1 \mathrm{mM} \mathrm{CuSO}_{4}$ and $50 \mu \mathrm{g} \mathrm{mL}^{-1}$ dsDNA were prepared. All stock solutions were stored at $-4{ }^{\circ} \mathrm{C}$ and solutions were prepared using analytical grade reagents and purified water from a Millipore Milli-Q system (conductivity $\leq 0.1 \mu \mathrm{S} \mathrm{cm}^{-1}$ ). All experiments were done at room temperature $\left(25 \pm 1^{\circ} \mathrm{C}\right)$.

Nitrogen and oxygen saturated solutions were obtained by bubbling high purity $\mathrm{N}_{2}$ or $\mathrm{O}_{2}$ for $10 \mathrm{~min}$ in the solution and continuing with a flow of pure gas over the solution during the voltammetric experiments.

HOPG, grade ZYH, of rectangular shape with $15 \mathrm{~mm} \times$ $15 \mathrm{~mm} \times 2 \mathrm{~mm}$ dimensions, from Advanced Ceramics Co., UK, was used in the AFM study as a substrate. The HOPG was freshly cleaved with adhesive tape prior each experiment and was imaged by AFM in order to establish its cleanliness.

\subsection{Atomic force microscopy experimental procedure}

AFM experiments were performed on thin and thick dsDNA films prepared using two immobilization procedures.

The thin film dsDNA was prepared by free adsorption from $100 \mu \mathrm{L}$ of $60 \mu \mathrm{g} / \mathrm{mL}$ dsDNA solution in $\mathrm{pH} 4.5,0.1 \mathrm{M}$ buffer acetate onto the HOPG surface and incubated for $3 \mathrm{~min}$. The adsorption process was stopped by gently rinsing the sample with a jet of Milli-Q water and the HOPG with adsorbed DNA was dried with nitrogen and imaged in air. 
The thick film dsDNA was prepared by evaporation of three consecutive drops on the surface of the HOPG, each containing $5 \mu \mathrm{L}$ of $50 \mu \mathrm{g} / \mathrm{mL}$ dsDNA in $\mathrm{pH} 4.5,0.1 \mathrm{M}$ acetate buffer electrolyte. After placing each drop on the surface, the biosensor was allowed to dry in a sterile atmosphere.

AFM was performed with a Pico SPM controlled by a MAC Mode module and interfaced with a PicoScan controller from Molecular Imaging Co., USA. All the AFM experiments were performed with a CS AFM S scanner with the scan range $6 \mu \mathrm{m}$ in $x-y$ and $2 \mu \mathrm{m}$ in $z$, Molecular Imaging Co. Silicon type II MAClevers $225 \mu \mathrm{m}$ length, $2.8 \mathrm{~N} / \mathrm{m}$ spring constant and $60-90 \mathrm{kHz}$ resonant frequencies (Molecular Imaging Co.) were used. All images were taken at room temperature, scan rates $1.0-1.3$ lines $\mathrm{s}^{-1}$. The images were processed by flattening in order to remove the background slope and the contrast and brightness were adjusted. All images were visualised in three dimensions using the Scanning Probe Image Processor, SPIP, and Version 2.3011, Image Metrology ApS, Denmark. Section analyses over dsDNA films as well as rms roughness measurements were performed with PicoScan software Version 6.0, Molecular Imaging Co.

\subsection{Voltammetric parameters and electrochemical cells}

All voltammetric experiments were done using an $\mu$ Autolab running with GPES Version 4.8 software, EcoChemie, Utrecht, The Netherlands. The experimental conditions unless stated otherwise were: differential pulse voltammetry (DPV), pulse amplitude $50 \mathrm{mV}$, pulse width $70 \mathrm{~ms}$ and scan rate $5 \mathrm{mV} \mathrm{s}^{-1}$.

To study the interaction between quercetin and quercetin- $\mathrm{Cu}(\mathrm{II})$ complexes with DNA a glassy carbon (GCE) $(d=1.5 \mathrm{~mm})$ working electrode, a Pt wire counter electrode and a $\mathrm{Ag} / \mathrm{AgCl}$ (saturated $\mathrm{KCl}$ ) as reference were used in a $0.5 \mathrm{~mL}$ one-compartment electrochemical cell.

To study the interaction between adriamycin and DNA, a glassy carbon $(d=6 \mathrm{~mm})$ working electrode, a Pt wire counter electrode and a saturated calomel electrode (SCE) as reference were used in a $5 \mathrm{~mL}$ one-compartment electrochemical cell.

Microvolumes were measured using EP-10 and EP-100 Plus Motorized Microliter Pippettes (Rainin Instrument Co. Inc., Woburn, USA). The $\mathrm{pH}$ measurements were carried out with a Crison micropH $2001 \mathrm{pH}-$ meter with an Ingold combined glass electrode. All the experiments were done at room temperature.

\subsection{GCE modification}

Two GCE modification methodologies with dsDNA were used.

The thin film dsDNA-biosensor was prepared by immersing the GCE in a $60 \mu \mathrm{g} / \mathrm{mL}$ dsDNA solution and applying a potential of $+0.40 \mathrm{~V}$ during $10 \mathrm{~min}$. After this surface modification step, the biosensor was electrochemically conditioned [7] in $\mathrm{pH} 4.5,0.1 \mathrm{M}$ acetate buffer electrolyte solution until a reproducible baseline was obtained.

The thick film dsDNA-biosensor was prepared by successively covering the GCE $(d=1.5 \mathrm{~mm})$ surface with three drops of $5 \mu \mathrm{L}$ each containing $50 \mu \mathrm{g} / \mathrm{mL}$ dsDNA. After placing each drop on the electrode surface the biosensor was allowed to dry.

\subsection{Acquisition and presentation of voltammetric data}

All the experimental curves presented were backgroundsubtracted and baseline corrected using the moving average application with a step window of $10 \mathrm{mV}$ included in GPES Version 4.9 software. This mathematical treatment improves the visualisation and identification of peaks over the baseline without introducing any artefact.

Origin (Version 6.0) from Microcal Software was used for the presentation of all the experimental voltammograms reported in this work.

\section{Results and discussion}

\subsection{Atomic force microscopy surface characterization}

In order to obtain a DNA electrochemical biosensor with high stability, selectivity and sensibility, the characterization of the surface of the nanoscale DNA adsorbed film is essential. MAC Mode AFM was used to investigate the two different methods of preparing DNA electrochemical biosensors onto HOPG, in order to morphologically characterize the DNA-biosensor surface, and better understand the nanoscale film formed on the electrode surface. HOPG was used as substrate, because it is easy to clean, inert in air and has extremely smooth terraces on its basal plane, which represents an important requirement for imaging biological molecules [1].

The thin film dsDNA-biosensor was prepared by free adsorption, as described in Section 2. The MAC Mode AFM images in air showed that the DNA molecules cover the HOPG electrode, forming a thin molecular network film of $0.94 \pm 0.2 \mathrm{~nm}$ thickness (Fig. 1). The DNA film presented pores that left the HOPG surface uncovered, showing a rms roughness of $1.3 \mathrm{~nm}$, a value obtained on a $3 \mu \mathrm{m} \times 3 \mu \mathrm{m}$ scan size area.

The thick film dsDNA-biosensor was prepared by adsorption from a more concentrated dsDNA solution to enable complete electrode surface coverage, thus avoiding nonspecific adsorption on the carbon surface. The immobilization method consisted of evaporation onto the previously cleaved HOPG surface of three consecutive drops, as described in Section 2.

After complete dehydration of the dsDNA, the HOPG electrode was completely covered by a thick dsDNA film. The MAC Mode AFM images revealed a complete coverage of the electrode surface (Fig. 2A) with uniformly distributed peaks and valleys (Fig. 2C and D). As observed from sec- 

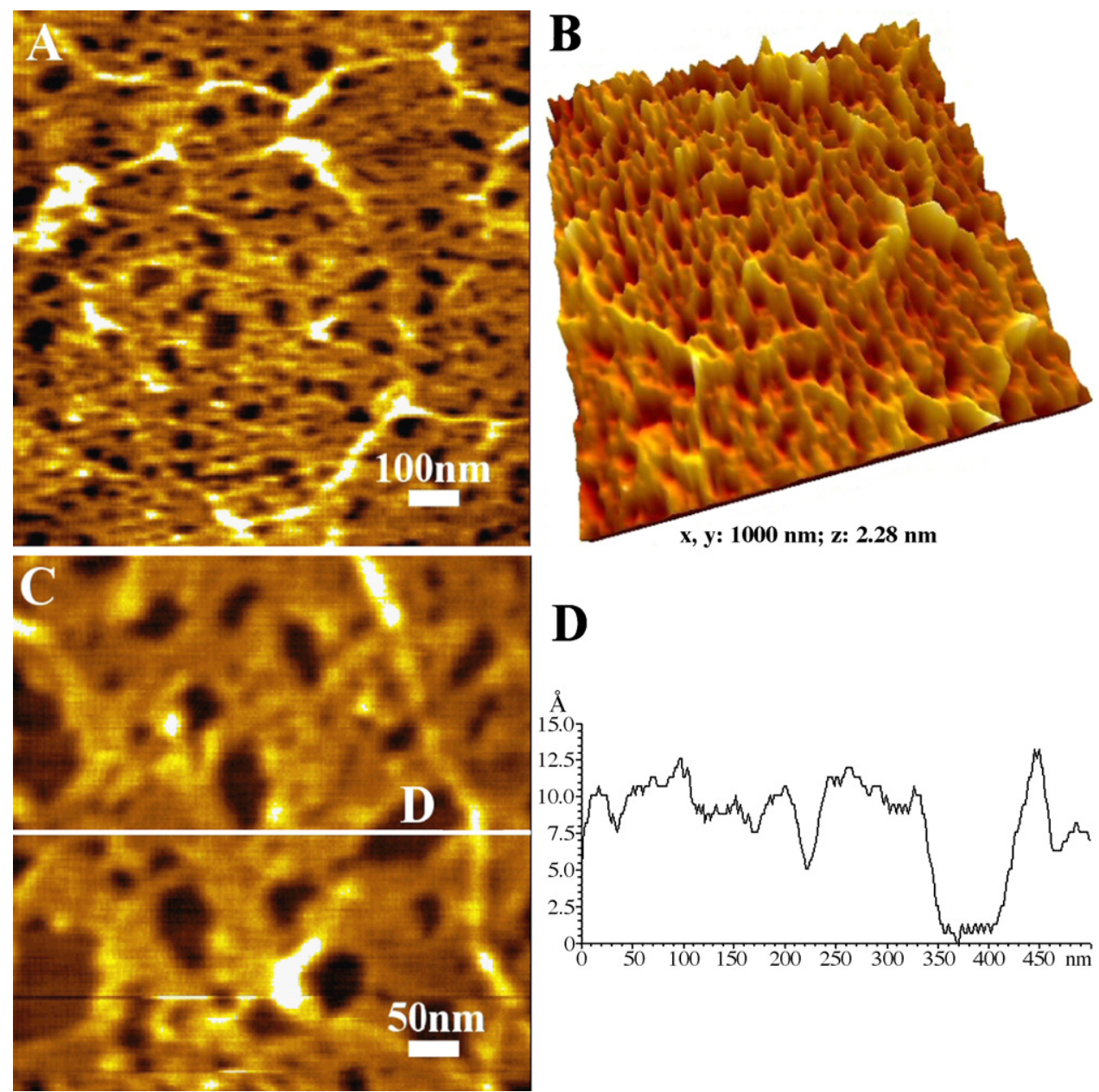

Fig. 1. (A and C) MAC Mode AFM topographical images in air of thin film dsDNA-biosensor surface, prepared onto HOPG by 3 min free adsorption from a solution of $60 \mu \mathrm{g} / \mathrm{mL}$ dsDNA in $\mathrm{pH} 4.5,0.1 \mathrm{M}$ acetate buffer electrolyte; (B) three-dimensional representation of image 'A'; (D) cross-section profile through white line in image ' $C$ '.

tion analysis profiles performed at different locations on the dsDNA film, the adsorbed film presented nuclei of many different sizes, with 5-150 $\mathrm{nm}$ height, and 10-300 nm diameter measured at half height (Fig. 2B). The rms roughness, calculated on the $3 \mu \mathrm{m} \times 3 \mu \mathrm{m}$ scan size area from Fig. 2A, was $23.2 \mathrm{~nm}$. In this case the electrode is completely protected by the dsDNA film. Consequently the adsorption of undesired molecules on the electrode surface is not possible, and the DNA-biosensor response can only be from the interaction of the compound with the dsDNA.

\subsection{The influence of oxygen on DNA damage}

The maintenance of the genomic integrity and of the transcription processes is essential for correct cell functioning. Reactive oxygen species have a central role in oxidative stress, which leads to biomolecular damage. The understanding of the mechanisms involved in DNA oxidative damage caused by ROS is of great interest. In particular, it is important to study the influence of ROS on the interaction of several compounds with DNA that can improve the knowledge of DNA-target-directed-drugs and the role played by various compounds present in food which show anti-oxidative activity.

The DNA-biosensor is suitable for investigating the influence of ROS on the DNA damage caused by the oxidative activity of quercetin and the anticancer drug adriamycin. The dsDNA damage is detected by changes of the electrochemical behaviour of immobilized dsDNA, specifically through changes detected in purinic bases oxidation peak currents [2].

\subsubsection{Quercetin}

The redox activity of quercetin has been extensively studied [18]. A DP voltammogram obtained in buffer after free adsorption during $10 \mathrm{~min}$ in a $100 \mu \mathrm{M}$ quercetin solution is shown in Fig. 3(dotted line). The main oxidation peak of quercetin occurs at $E_{\mathrm{pa}}=+0.32 \mathrm{~V}$, corresponding to oxidation of the $3^{\prime}, 4^{\prime}$-dihidroxy groups on the ring $\mathrm{B}$, and is followed by a smaller signal at $E_{\mathrm{pa}}=+0.98 \mathrm{~V}$ due to the oxidation of the 5,7-dihydroxy substituent on ring A.

A thick film dsDNA-biosensor was prepared as described in Section 2.4, by successively covering the GCE surface 

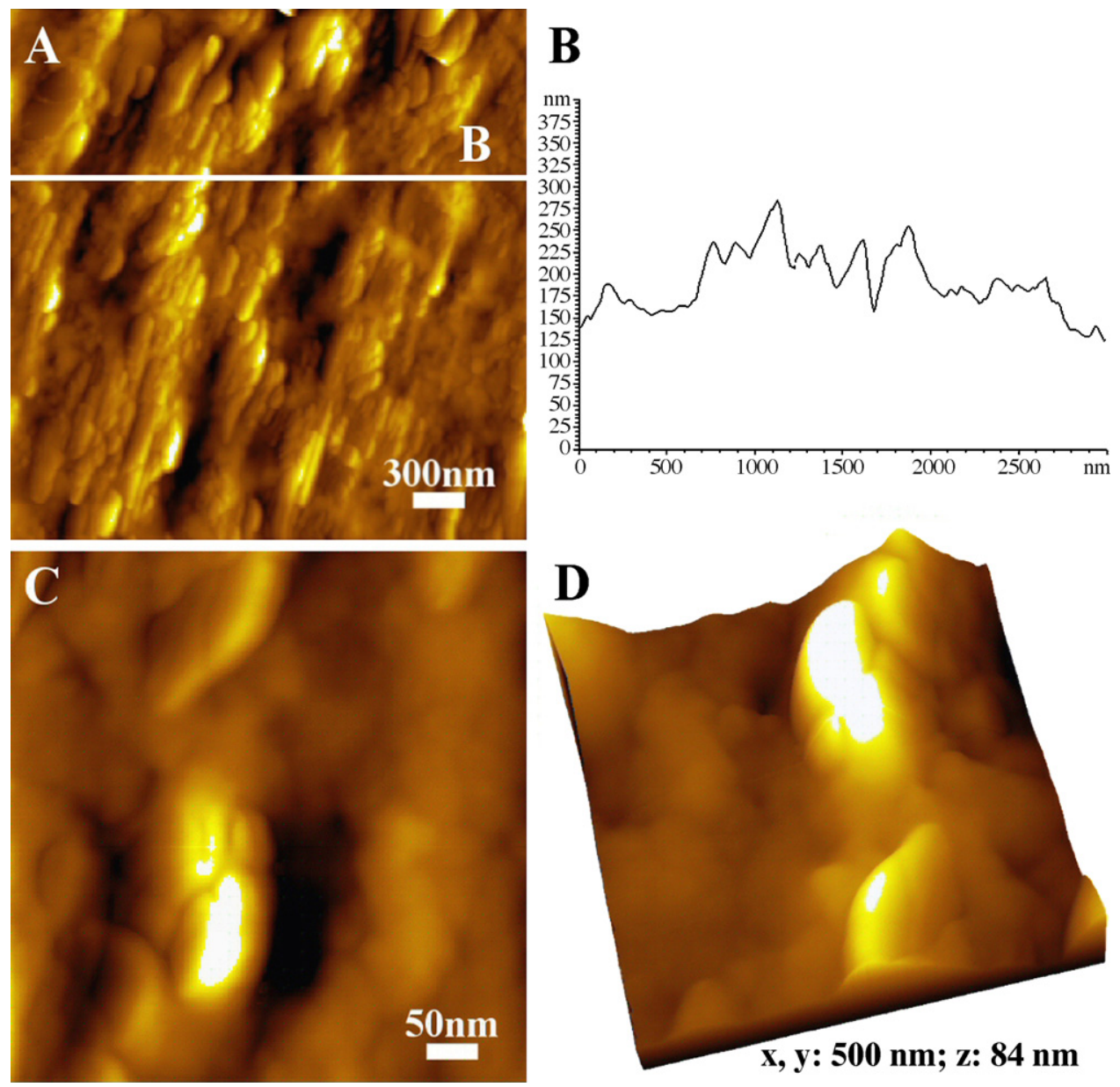

Fig. 2. (A and C) MAC Mode AFM topographical images in air of thick film dsDNA-biosensor surface, prepared onto HOPG by evaporation of three consecutive drops each containing $5 \mu \mathrm{L}$ of $50 \mu \mathrm{g} / \mathrm{mL}$ dsDNA in $\mathrm{pH} 4.5,0.1 \mathrm{M}$ acetate buffer electrolyte; (B) cross-section profile through white line in image 'A'; (D) three-dimensional representation of image ' $\mathrm{C}$ '.

with three drops of dsDNA. After placing each drop on the electrode surface the biosensor was allowed to dry, leading to formation of a multilayer film of dsDNA immobilized on the GCE surface which covers it completely, as observed in the AFM images from Fig. 2.

The DP voltammogram obtained using the thick film DNA-biosensor in buffer (Fig. 3(thick line)) showed two tiny signals corresponding to the oxidation of guanosine (Guo), $E_{\mathrm{pa}}=+1.02 \mathrm{~V}$, and adenosine (Ado), $E_{\mathrm{pa}}=+1.27 \mathrm{~V}$ [19] residues in the polynucleotide chain.

The interaction between dsDNA and quercetin or quercetin- $\mathrm{Cu}(\mathrm{II})$ complexes at a thick film dsDNAbiosensor was followed by DP voltammetry (Fig. 4). The DNA-biosensor was incubated during $10 \mathrm{~min}$ in a solution of $100 \mu \mathrm{M}$ quercetin and then transferred to acetate buffer. The main oxidation peak of quercetin is followed by the small peaks due to oxidation of guanosine and adenosine (Fig. 4(dotted line)). This DP voltammogram in buffer solution shows, as already described $[9,10]$, that intercalation of quercetin molecules into the immobilized DNA occurred without damaging the DNA double helix. However, since extensive quercetin-induced DNA damage via reaction with
$\mathrm{Cu}$ (II) ions has been reported [13], an electrochemical study of the DNA-quercetin- $\mathrm{Cu}$ (II) system was undertaken, and the effect of oxygen on the mechanism investigated.

The DNA-biosensor was held for $10 \mathrm{~min}$ in a solution of $100 \mu \mathrm{M}$ quercetin previously incubated for $30 \mathrm{~min}$ with $50 \mu \mathrm{M} \mathrm{CuSO}_{4}$ to form the quercetin-Cu(II) complexes. The biosensor was then thoroughly washed with deionized water in order to remove the non-intercalated molecules and transferred to acetate buffer where the DP voltammogram was recorded. The results obtained (Fig. 4(dotted line)) show that the quercetin peak still appears but with a smaller current and a new peak appears at $E_{\mathrm{pa}}=+0.45 \mathrm{~V}$. This peak has to be the product of the quercetin- $\mathrm{Cu}(\mathrm{II})$ complex interaction with DNA and the value of potential coincides with that for oxidation of 8-oxodGuo [14]. The peaks corresponding to guanosine and adenosine oxidation are several times higher than those obtained after the DNA-biosensor incubation in quercetin solution (Fig. 4(dashed line)). This clearly showed that greater modification to the dsDNA film has occurred after the interaction of DNA with quercetin- $\mathrm{Cu}$ (II) complex.

It is known that the reduction of the $\mathrm{Cu}$ (II) ions by quercetin [13] leads to formation of quercetin radicals which 


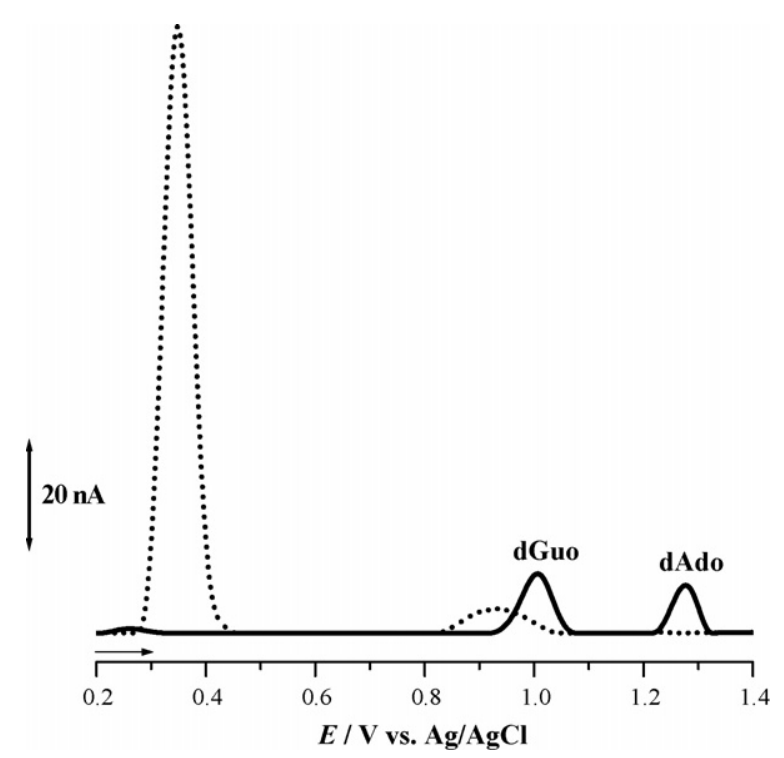

Fig. 3. Base line corrected differential pulse voltammograms obtained in $\mathrm{pH}$ 4.5, 0.1 M acetate buffer: ( $)$ thick film DNA-biosensor and (•.• ) GCE previously modified by immersion during $10 \mathrm{~min}$ in a solution of $100 \mu \mathrm{M}$ quercetin. Scan rate $5 \mathrm{mV} \mathrm{s}^{-1}$, pulse amplitude $50 \mathrm{mV}$ and pulse width $0.07 \mathrm{~s}$.

react with oxygen forming ROS that in turn have the ability to damage DNA [20]. In order to prove the involvement of the oxygen radicals in the process of DNA damage during interaction with quercetin- $\mathrm{Cu}(\mathrm{II})$, the experiment described above was repeated in solutions saturated with $\mathrm{N}_{2}$.

The DNA-biosensor was kept during $10 \mathrm{~min}$ in a solution of $100 \mu \mathrm{M}$ quercetin previously incubated for $30 \mathrm{~min}$ with $50 \mu \mathrm{M} \mathrm{CuSO}_{4}$ in a constant flux of $\mathrm{N}_{2}$ in order to saturate the $\mathrm{pH} 4.5,0.1 \mathrm{M}$ acetate buffer solution. In this way, the

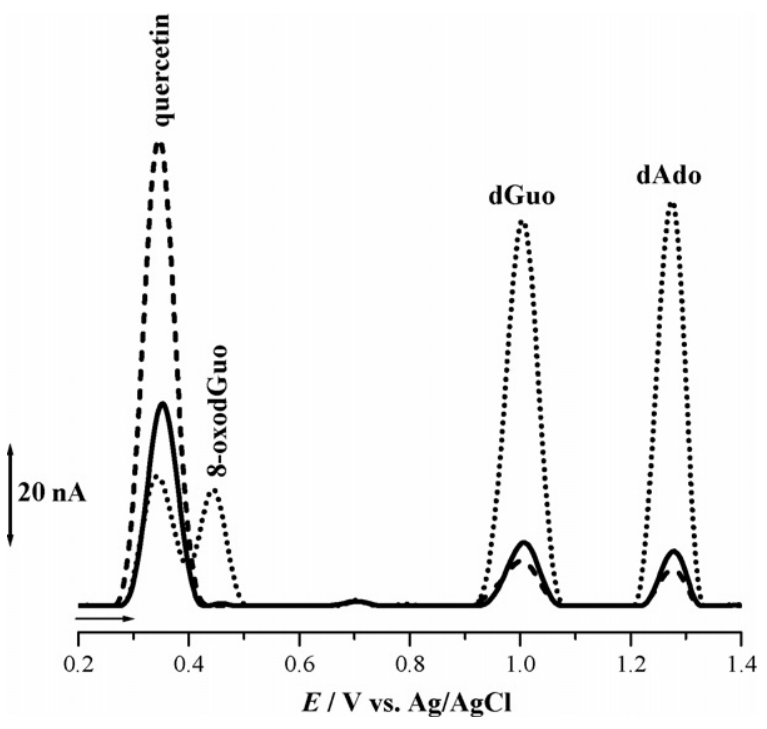

Fig. 4. Base line corrected differential pulse voltammograms obtained in $\mathrm{pH}$ 4.5, 0.1 M acetate buffer with a thick film DNA-biosensor after immersion for $10 \mathrm{~min}$ in: (-.. ) $100 \mu \mathrm{M}$ quercetin, (•••) $100 \mu \mathrm{M}$ quercetin incubated for 30 min with $50 \mu \mathrm{M} \mathrm{CuSO}$ in normal atmosphere and (- ) $100 \mu \mathrm{M}$ quercetin incubated for $30 \mathrm{~min}$ with $50 \mu \mathrm{M} \mathrm{CuSO}_{4}$ in $\mathrm{N}_{2}$-saturated solution. Scan rate $5 \mathrm{mV} \mathrm{s}^{-1}$, pulse amplitude $50 \mathrm{mV}$ and pulse width $0.07 \mathrm{~s}$.
$\mathrm{O}_{2}$ was removed from the solution and the quercetin radicals formed during the oxidation of quercetin by $\mathrm{Cu}$ (II) ions could not react with oxygen and no ROS were formed to damage the DNA film. After this incubation procedure, the biosensor was washed with deionized water and transferred to buffer. The DP voltammogram obtained in these conditions showed only a small oxidation peak of guanosine and adenosine proving that no DNA damage had occurred (Fig. 4(thick line)). Also, no additional peak, specifically at $E_{\mathrm{pa}}=+0.45 \mathrm{~V}$ was observed, although a small quercetin oxidation peak 1 occurred.

At the end of each experiment, the dsDNA film was removed and the electrode was placed in acetate buffer where a DP voltammogram was recorded. No quercetin oxidation peak was observed, confirming that all the peaks were due to the DNA-intercalated quercetin or quercetin-Cu(II) complex ions. This proves that the layer-by-layer prepared thick DNA film completely covered the GCE surface as shown in the AFM image in Fig. 2.

\subsubsection{Adriamycin}

The electrochemical DNA-biosensor also enabled the study of the mechanism of interaction of the anti-neoplasic drug adriamycin with DNA $[7,8]$. It was possible to use the DNA-biosensor to mimic several cell situations through the in situ electrochemical generation of the reactive adriamycin semiquinone radical in the presence or absence of molecular oxygen.

To study the effect of $\mathrm{O}_{2}$ on the mechanism of action of adriamycin when intercalated in dsDNA, the thin film DNA-biosensor described in Section 2.4 was used. A nonuniform thin nanoscale DNA film was adsorbed onto the GCE leaving many uncovered regions as demonstrated by AFM imaging (Fig. 1). In all experiments, the thin film DNAbiosensor was immersed during $3 \mathrm{~min}$ in $5 \mu \mathrm{M}$ adriamycin solution, rinsed with water and then transferred to buffer, where DP voltammetry was performed (Fig. 5). Each experiment was performed with a newly prepared DNA-biosensor, the differences in surface area of the DNA network-modified GCE leading to the variations observed in the adriamycin peak current.

In the first experiment a current peak attributed to adriamycin oxidation at $+0.50 \mathrm{~V}$ (Adr) $[7,8,15]$, and a small peak attributed to deoxiguanosine (dGuo) oxidation at $+0.90 \mathrm{~V}$ [19] were obtained in the absence of $\mathrm{O}_{2}\left(\mathrm{~N}_{2}\right.$ saturated electrolyte buffer solution) (Fig. 5(thick line)).

In another experiment, also in the absence of $\mathrm{O}_{2}$, a potential of $-0.60 \mathrm{~V}$ was applied during $60 \mathrm{~s}$ before the beginning of the potential scan, and a slight increase of the current peak for adriamycin oxidation was observed, due to reorientation of the adriamycin molecules adsorbed in the network pores and the pre-concentration effect during the adsorption period at the applied potential. A new current peak at $+0.38 \mathrm{~V}$ was detected (Fig. 5(dotted line)). This peak was attributed to the oxidation 8-oxodGuo [14], and confirmed by spiking the solution with a standard solution of 8-oxodGuo. 


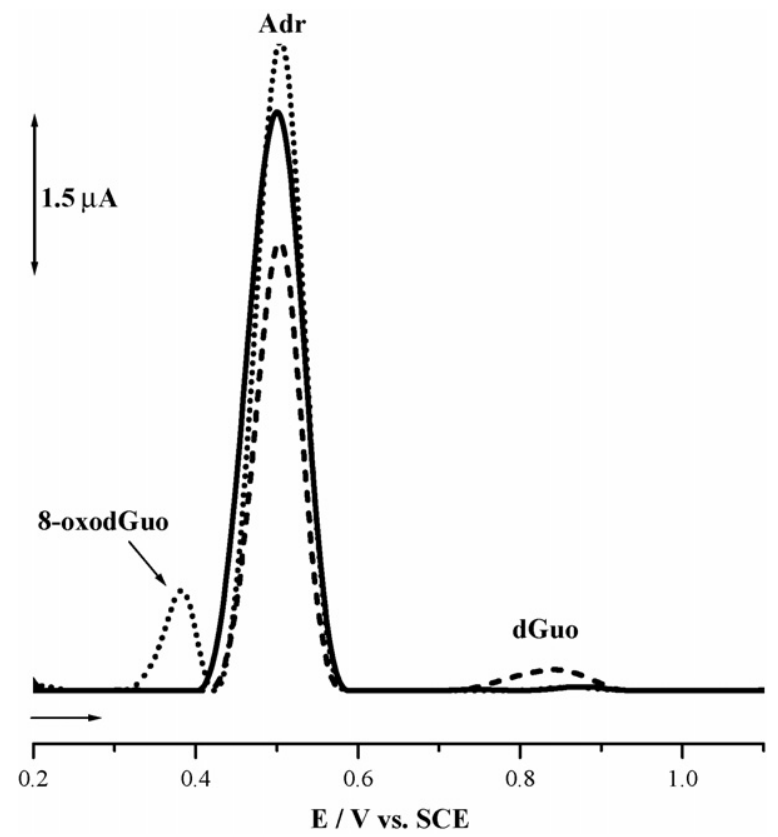

Fig. 5. Base line corrected differential pulse voltammograms in $\mathrm{pH} 4.5$, $0.1 \mathrm{M}$ acetate buffer with a thin film DNA-biosensor after immersion for $3 \mathrm{~min}$ in a $5 \mu \mathrm{M}$ adriamycin (Adr) solution and rinsed with water before the experiment in buffer electrolyte solution in: (-) $\mathrm{N}_{2}$ saturated solution

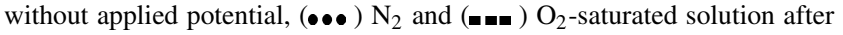
applying a potential of $-0.60 \mathrm{~V}$ during $60 \mathrm{~s}$. Pulse amplitude $50 \mathrm{mV}$, pulse width $0.07 \mathrm{~s}$ and scan rate $5 \mathrm{mV} \mathrm{s}^{-1}$. First scans.

The DP voltammogram obtained with the thin film DNA-biosensor in the presence of $\mathrm{O}_{2} \quad\left(\mathrm{O}_{2}\right.$ saturated electrolyte buffer solution) after applying a potential of $-0.60 \mathrm{~V}$ during $60 \mathrm{~s}$ (Fig. 5(dashed line)) showed different features from those observed in the absence of $\mathrm{O}_{2}\left(\mathrm{~N}_{2}\right.$ saturated electrolyte buffer solution). The current peak due to 8-oxodGuo oxidation is absent. There was also a decrease in the height of the adriamycin oxidation peak, in the presence of $\mathrm{O}_{2}$, and a peak attributed to deoxiguanosine (dGuo) oxidation at $+0.85 \mathrm{~V}$ [19] appeared. A similar result was obtained when no potential was applied and the other conditions were kept the same.

These results suggest that the presence of a large amount of $\mathrm{O}_{2}$ causes interference to the adriamycin-DNA interaction pathway. In fact, when $-0.60 \mathrm{~V}$ is applied to the biosensor previously incubated in a $5 \mu \mathrm{M}$ adriamycin solution, the simultaneous generation of superoxide anion and of adriamycin semiquinone radicals occurs. Adriamycin- $\mathrm{O}_{2}$ redox-cycling process leads to the regeneration of adriamycin through oxidation of the semiquinone radical by molecular oxygen, and the concomitant production of the superoxide anion radical.

It has been shown that adriamycin intercalates between base pairs in dsDNA and preferentially at $\mathrm{CpG}$ homologous sequences [21]. This disrupts the double helix locally and exposes guanine residues which can then easily undergo oxidation at the electrode surface explaining the dGuo oxidation peak observed. The semiquinone radical is formed when $-0.60 \mathrm{~V}$ is applied but is immediately oxidised by the $\mathrm{O}_{2}$ (present in high concentration) regenerating adriamycin. Because of this regeneration, the guanine moiety near the adriamycin intercalation point in dsDNA cannot be oxidised by the radical. Therefore, the concentration of 8-oxodGuo is very low, below the limit of detection of 8-oxodGuo by DP voltammetry [14,22,23] and no peak for 8-oxodGuo is observed. The opposite happens in the absence of $\mathrm{O}_{2}$, where 8 -oxodGuo is formed and is detected by DP voltammetry (Fig. 5(dotted line)).

It is known that the adriamycin- $\mathrm{O}_{2}$ redox-cycling process primarily increases the amount of superoxide anion radical that has a long range of action but a weak capacity to cause oxidative damage in biological macromolecules [24]. Therefore, it is not surprising that 8-oxodGuo was not generated through superoxide attack on guanine residues of the dsDNA in the thin film. Besides, it as been shown that other ROS, like singlet oxygen and mostly the hydroxyl radical, contribute more to in vivo and in vitro 8-oxodGuo generation than the superoxide anion radical [24].

The results obtained in the absence of $\mathrm{O}_{2}$ are similar to those obtained previously in normal atmosphere but using a thick film DNA-modified GCE (Fig. 2) which led to the proposal of a mechanistic model for the generation of 8-oxodGuo by adriamycin intercalated in dsDNA after in situ generation, at $-0.60 \mathrm{~V}$, of the semiquinone adriamycin radical [7]. However, the thin film DNA-biosensor enabled much better detection of the oxidation peak of 8-oxodGuo which was difficult to identify with the thick film DNA-biosensor $[7,8]$. The present results are in agreement with the proposed mechanistic model [7] confirming that adriamycin, through its semiquinone radical, is able to directly cause oxidative damage to DNA. Consequently, any cellular process that enhances the in vivo production of the semiquinone adriamycin radical $[7,8,17]$ contributes indirectly to this genomic mutagenic lesion which can ultimately lead to cell malfunction.

\section{Conclusions}

Using ex situ MAC mode AFM in air the characteristics of the nanoscale dsDNA electrochemical biosensor surface film on HOPG was investigated. Two DNA-biosensors were prepared, thin and thick dsDNA films with different morphological properties.

The thick and thin film DNA-biosensors enabled clarification of the influence of ROS in the mechanism of DNA oxidative damage caused by the flavonoid quercetin and the anthracycline adriamycin, by monitoring the detection of 8-oxodGuo a major product of DNA oxidative damage. Quercetin caused DNA oxidative damage in the presence of $\mathrm{Cu}(\mathrm{II})$, the quercetin- $\mathrm{Cu}(\mathrm{II})$ complex binding to the dsDNA and the ROS formed during oxidation of quercetin by the $\mathrm{Cu}$ (II) ions attacking the dsDNA thus disrupting the helix and leading to the formation of 8-oxodGuo. Adriamycin caused 
direct oxidative damage on dsDNA through its semiquinone radical intercalated in the double helix which oxidises guanine residues and generates 8-oxodGuo in a mechanism in which ROS are not directly involved.

Thus, it was shown that both compounds were able to cause oxidative damage to DNA generating 8-oxodGuo, but the influence of ROS in the overall reaction mechanisms was different. The electrochemical dsDNA-biosensors were an essential research tool to clarify and confirm these mechanisms.

\section{Acknowledgements}

Financial support from Fundação para a Ciência e Tecnologia (FCT), Post-Doctoral Grant SFRH/BPD/14425/2003 (A.-M.C.P.), Ph.D. Grants PRAXIS XXI/BD/6134/2001 (J.A.P.P.), and PRAXIS SFRH/BD/877/2000 (V.C.D.), POCTI (cofinanced by the European Community Fund FEDER), ICEMS (Research Unit 103) and European Project HPRN-CT-2002-00186 is gratefully acknowledged.

\section{References}

[1] Oliveira Brett AM, Chiorcea A-M. Atomic force microscopy of DNA immobilized onto a highly oriented pyrolytic graphite electrode surface. Langmuir 2003;19:3830-9.

[2] Oliveira-Brett AM. DNA-based biosensors. In: Gordon L, editor. Comprehensive analytical chemistry, biosensors and modern specific analytical techniques. Elsevier; 2004 [chapter 8].

[3] Oliveira Brett AM, Serrano SHP, Gutz I, La-Scalea MA. Electrochemical reduction of metronidazole at a DNA-modified glassy carbon electrode. Bioelectrochem Bioenerg 1997;42:175-8.

[4] Oliveira Brett AM, Macedo TA, Raimundo D, Marques MH, Serrano SHP. Voltammetric behaviour of mitoxandrone at a DNA-biosensor. Biosens Bioelectron 1998;13:861-7.

[5] Oliveira Brett AM, da Silva LA, Fujii H, Mataka S, Thiemann T. Detection of the damage caused to DNA by a thiophene-S-oxide using an electrochemical DNA-biosensor. J Electroanal Chem 2003;549:91-9.

[6] Abreu FC, Goulart MOF, Oliveira Brett AM. Detection of the damage caused to DNA by niclosamide using an electrochemical DNAbiosensor. Biosens Bioelectron 2002;17:913-9.

[7] Oliveira Brett AM, Vivan M, Fernandes IR, Piedade JAP. Electrochemical detection of in situ adriamycin oxidative damage to DNA. Talanta 2002;56:959-70.
[8] Piedade JAP, Fernandes IR, Oliveira Brett AM. Electrochemical sensing of DNA-adriamycin interactions. Bioelectrochemistry 2002;56:81-3.

[9] Oliveira Brett AM, Diculescu VC. Electrochemical study of quercetin-DNA interaction: Part I. Analysis in incubated solutions. Bioelectrochemistry 2004;64:133-41.

[10] Oliveira Brett AM, Diculescu VC. Electrochemical study of quercetin-DNA interaction: Part II. In situ sensing with DNA biosensor. Bioelectrochemistry 2004;64:143-50.

[11] Ohshima H, Yoshie Y, Auriol S, Gilibert I. Antioxidant and prooxidant actions of flavonoids: effects on DNA damage induced by nitric oxide, peroxynitrite and nitroxyl anion. Free Radic Biol Med 1998;25:1057-65.

[12] Johnson MK, Loo G. Effects of epigallocatechin gallate and quercetin on oxidative damage to cellular DNA. Mutat Res/DNA Repair 2000;459(3):211-8.

[13] Rahman A, Shahabuddin S, Hadi SM, Parish JH. Complexes involving quercetin, DNA and $\mathrm{Cu}(\mathrm{II})$. Carcinogenesis 1990;11:2001-3.

[14] Oliveira Brett AM, Piedade JAP, Serrano SHP. Electrochemical oxidation of 8-oxoguanine. Electroanalysis 2000;12:969-73.

[15] Oliveira Brett AM, Piedade JAP, Chiorcea AM. Anodic voltammetry and AFM imaging of picomoles of adriamycin adsorbed onto carbon surfaces. J Electroanal Chem 2002;538-539:267-76.

[16] Berg H, Horn G, Luthardt U. Interaction of anthracycline antibiotics with biopolymers. Part V. Polarographic behavior and complexes with DNA. Bioelectrochem Bioenerg 1981;8:537-53.

[17] Lown JW. Discovery and development of anthracycline antitumour antibiotics. Chem Soc Rev 1993:165-76.

[18] Oliveira Brett AM, Ghica M-E. Electrochemical oxidation of quercetin. Electroanalysis 2003;15:1745-50.

[19] Oliveira Brett AM, Piedade JAP, Silva LA, Diculescu VC. Voltammetric determination of all DNA nucleotides. Anal Biochem 2004;332:969-73.

[20] Box HC, Dawindzik JB, Budzinski EE. Free radical-induced double lesions in DNA. Free Radic Biol Med 2001;31:856-68.

[21] Culliname C, Phillips DR. Induction of stable transcriptional blockage sites by adriamycin: $\mathrm{GpC}$ specificity of apparent adriamycin-DNA adducts and dependence on iron(III) ions. Biochemistry 1990;29:5638-46.

[22] ESCOOD (European Standards Committee on Oxidative DNA Damage). Comparison of different methods of measuring 8-oxoguanine as a marker of oxidative DNA damage. Free Radic Res 2000;32:33341.

[23] Rebelo IA, Piedade JAP, Oliveira-Brett AM. Development of an HPLC method with electrochemical detection of femtomoles of 8-oxo-7,8dihydroguanine and 8-oxo-7,8-dihydro-2'-deoxyguanosine in the presence of uric acid. Talanta 2004;63:323-31.

[24] Halliwell B. Oxygen and nitrogen are pro-carcinogens. Damage to DNA by reactive oxygen, chlorine and nitrogen species: measurement, mechanism and the effects of nutrition. Mutat Res 1999;443:37-52. 